\title{
Coronary artery bypass grafting in patients with diabetes: The weight is on us
}

\author{
Mani Arsalan, $\mathrm{MD},{ }^{\mathrm{a}}$ and Michael Mack, $\mathrm{MD}^{\mathrm{b}}$
}

See related article on pages 304-12.

The incidence of diabetes mellitus (DM) has increased to near epidemic proportions over the past 40 years. In 2010, approximately 285 million people worldwide had DM, a number that has more than doubled in the past 3 decades. ${ }^{1,2}$ According to the 2014 National Diabetes Statistics Report, 29.1 million people, or $9.3 \%$ of the population, have diabetes in the United States. This high prevalence of diabetes is associated with increased costs for the community. In addition to $\$ 176$ billion in direct medical costs, an estimated $\$ 69$ billion was lost to reduced productivity in $2012 .^{3}$

Patients with diabetes, with or without metabolic syndrome, represent an increasing challenge for cardiac surgery. Because of both the increasing incidence of the disease and the recent studies showing that patients with DM and multivessel disease have a mortality benefit when treated by coronary artery bypass grafting (CABG) compared with percutaneous coronary intervention, the number of patients undergoing surgical revascularization can be expected to continue to increase.

It is against this background that the study by Raza and colleagues $^{5}$ from the Cleveland Clinic is especially relevant. In this carefully performed and detailed study, they report the outcomes of more than 57,000 patients undergoing $\mathrm{CABG}$ in their institution over 4 decades. They specifically compared the outcomes of patients with pharmacologically treated (insulin or oral hypoglycemic agents) DM (10,362 patients) with those undergoing CABG without treatment for diabetes. They confirmed what most clinicians already know and multiple studies have shown: The outcomes of patients with diabetes are worse than those of nondiabetic patients. However, what is particularly important about this study is that it is a single institutional experience with known surgical excellence and meticulous and complete outcomes database.

$\overline{\text { From }{ }^{\mathrm{a} C} \text { Cardiovascular Surgery and }}{ }^{\mathrm{b}}$ Cardiac Research, Heart Hospital Baylor Plano, Baylor Research Institute, Baylor Scott \& White Health, Dallas, Tex.

Disclosures: Authors have nothing to disclose with regard to commercial support.

Received for publication May 12, 2015; accepted for publication May 14, 2015; available ahead of print June 19, 2015.

Address for reprints: Michael Mack, MD, 1100 Allied Dr, Plano, TX 75075 (E-mail: michael.mack@baylorhealth.edu).

J Thorac Cardiovasc Surg 2015;150:284-5

$0022-5223 / \$ 36.00$

Copyright (c) 2015 by The American Association for Thoracic Surgery

http://dx.doi.org/10.1016/j.jtcvs.2015.05.046
The following are the noteworthy findings from their study:

1. The incidence of diabetes in patients undergoing

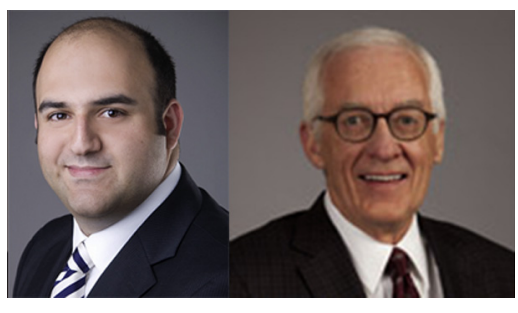
CABG increased 5 -fold over 4 decades.

2. Diabetic patients had a higher in-hospital mortality and long-term mortality at 5, 10, and 20 years.

3. Bilateral internal thoracic arteries were used in only $8 \%$ of diabetic patients.

4. Diabetic patients had a significantly higher incidence of complications, including deep sternal wound infection, stroke, renal failure, and prolonged postoperative hospital stay.

5. Diabetic patients also had significantly higher hospital costs than nondiabetic patients.

Given these findings and the fact that CABG can be expected to remain the mainstay of treatment of multivessel coronary artery disease in diabetic patients because of the results of the Future Revascularization Evaluation in Patients With Diabetes Mellitus: Optimal Management of Multivessel Disease (FREEDOM) trial, what are the lessons for surgeons to learn? Because there is higher early mortality and morbidity, and decreased long-term survival associated with CABG in diabetic patients, increased attention to the details of the procedure is called for. First, despite compelling evidence of survival benefit of bilateral internal thoracic arteries from the authors' own institution, the use of bilateral internal thoracic arteries remains distressingly low not only nationally but also at the institution that has championed their use despite a demonstrated $23 \%$ long-term mortality benefit. More than 15 years ago, another study from the Cleveland Clinic showed that survival of diabetic patients after CABG improves if both thoracic arteries are used. "Two arteries are better than one." ${ }^{6}$ This was confirmed in another recent study of Raza and colleagues. ${ }^{7}$ They showed that the use of bilateral internal thoracic arteries is associated with increasing complications, including sternal wound infection especially in female patients with morbid obesity and high atherosclerotic burden. Although everyone wants to minimize deep sternal wound infection, now a "never event" in quality outcomes reporting, it seems reasonable to use both internal thoracic arteries in those patients who are not an inordinate risk and stand most to benefit. 
Balancing the short-term risks with a long-term survival benefit should be encouraged in each diabetic patient. The use of skeletonized bilateral internal thoracic arteries in young, nonobese diabetic patients with a greater than 10 -year life expectancy is a reasonable risk to take. Perhaps in an elderly, morbidly obese female diabetic patient at high risk for sternal infection and shorter life expectancy, a single left internal thoracic artery would be best. Greater use of radial artery grafts to totally occluded or highly stenotic vessels also has been demonstrated to improve long-term survival. ${ }^{8}$ Postponing elective procedures until the hemoglobin A1c level is indicative of satisfactory glycemic control can help decrease early complications. Because patients with DM represent a disproportionate share of complications and healthcare costs, it behooves us to focus directly on helping these patients by minimizing operative risks and doing those things that have demonstrated evidence of long-term survival benefit. The weight may be increasingly on our patients, but the real weight is on us as surgeons to help improve their early and long-term survival.

\section{References}

1. Shaw JE, Sicree RA, Zimmet PZ. Global estimates of the prevalence of diabetes for 2010 and 2030. Diabetes Res Clin Pract. 2010;87:4-14.

2. Danaei G, Finucane MM, Lu Y, Singh GM, Cowan MJ, Paciorek CJ, et al. National, regional, and global trends in fasting plasma glucose and diabetes prevalence since 1980: systematic analysis of health examination surveys and epidemiological studies with 370 country-years and 2.7 million participants. Lancet. 2011;378:31-40.

3. American Diabetes Association. Economic costs of diabetes in the U.S. in 2012 Diabetes Care. 2013;36:1033-46.

4. Farkouh ME, Domanski M, Sleeper LA, Siami FS, Dangas G, Mack M, et al Strategies for multivessel revascularization in patients with diabetes. $N$ Engl J Med. 2012;367:2375-84

5. Raza S, Sabik JF, Ainkaran P, Blackstone EH. Coronary artery bypass grafting in diabetics: a growing healthcare cost crisis. J Thorac Cardiovasc Surg. 2015;150: 304-12.

6. Lytle BW, Blackstone EH, Loop FD, Houghtaling PL, Arnold JH, Akhrass R, et al Two internal thoracic artery grafts are better than one. J Thorac Cardiovasc Surg. 1999; 117:855-72.

7. Raza S, Sabik JF III, Masabni K, Ainkaran P, Lytle BW, Blackstone EH Surgical revascularization techniques that minimize surgical risk and maximize late survival after coronary artery bypass grafting in patients with diabetes mellitus. J Thorac Cardiovasc Surg. 2014;148:1257-66.

8. Deb S, Singh SK, Moussa F, Tsubota H, Une D, Kiss A, et al; Radial Artery Patency Study Investigators. The long-term impact of diabetes on graft patency after coronary artery bypass grafting surgery: a substudy of the multicenter Radial Artery Patency Study. J Thorac Cardiovasc Surg. 2014;148:1244-53. 